\title{
A MANPOWER PRODUCTIVITY MODEL FOR ORGANIZATIONAL EXCELLENCE: QUALITY AND ENTREPRENEURSHIP
}

\author{
Zohreh Mehtarizadeh ${ }^{1}$ Masoud Pourkiani ${ }^{2}$ \\ 1 PhD Student, Department of Management, Islamic Azad University, Address: Valiasr Blvd., Kerman, Iran. \\ Email:z.mehtarizadeh20@gmail.com \\ ${ }^{2}$ Assistant Professor, PhD, Department of Management, Islamic Azad University, Valiasr Blvd., Kerman, Iran. Email: \\ pourkiani@iauk.ac.ir
}

Received 1308 2020; Accepted 04112020

\begin{abstract}
This study aimed at explaining the effective indicators on human resource productivity for organizational excellence with an emphasis on quality and entrepreneurship. It is mixed research and descriptive-survey. The statistical population for compiling the indicators is the management specialists of the employees of Kerman organizations for evaluation. Data were analyzed using structural equation modeling and exploratory factor analysis. Research findings show that EFQM and entrepreneurship have a significant impact on manpower productivity management. Entrepreneurship also has an increasing and significant effect on EFQM. Therefore, by strengthening the indicators affecting the productivity of human resources and by emphasizing quality and entrepreneurship, we can take a step towards organizational excellence.
\end{abstract}

Keywords: Entrepreneurship, Manpower Productivity, Organizational Excellence, Quality, EFQM.

JEL Codes: M00, M10, J24, L26.

\section{Introduction}

Many organizations today are seeking excellence, but cannot achieve it due to the lack of a deep understanding of the concept of excellence and its criteria (Hashemy et al., 2016; Sergeevna \& Efimovna, 2020). Achieving greater competition is the primary goal of most organizations publicly and privately. Management excellence is a modern way that makes it possible (Suwandej, 2015; Baboli et al., 2020). Also, organizations are constantly challenged to improve their performance in every environment they operate (Zarei et al., 2020). They must, therefore, compare their performance with models and focus their efforts on their customers, so many organizations are moving towards holistic models; because comprehensive models are a useful tool through which organizations can compare their performance and determine to what extent the organization is nearing or is on the path to excellence (Kim et al., 2010). Undoubtedly, the growth and economic development of different societies lie in their productivity growth rates and this led many researchers and scholars to research in this field and related areas such as efficiency, effectiveness, quality, and customer satisfaction (Prasad et al., 2015).

Productivity, as a strategic approach, is among the main goals of organizations that build the economic growth foundation. It involves utilizing and integrating existing resources into a particular company, and as an essential step in developing and growth of an organization, can improve different systems and subsystems of the organization, and, measuring its productivity is one of the criteria for improving the organization; thus, productivity is considered the optimal use of company resources to achieve effective goals within the framework of an agreed value system (Alimohammadlou, Mohammadi, 2016). Organizations, even large corporations, include human beings and their human skills,

Copyright ( 2021 Author(s), published by Vytautas Magnus University. This is an open access article distributed under the terms of the Creative Commons Attribution Non-Commercial 4.0 (CC BY-NC 4.0) license, which permits unrestricted use, distribution, and reproduction in any medium provided the original author and source are credited. The material cannot be used for commercial purposes. 
characteristics, and motivations (Pokela, 2016).

Low productivity represents the waste of resources used by an organization, which eventually leads to international competition being eliminated, thereby reducing organizational business activities. One of the most important organizational resources is human resources. To create an efficient and capable human resource organization, organizational management has no other way but to focus on education, empowering creativity and initiative, raising morale and motivation, developing employee personality, and so on (Morgan, Hunt, 2007). The concept of employee productivity and its measures can be explained in different ways, as explained by Gupta (2008): viewpoint, quality of work, observation of individual functions, crossexamination of employee attitudes, review of employee personal services, time Job performance, achievement of goals, quality of work, employee collaboration, employee quality of work, productivity and levels of output or productivity (Bett, 2017; Moghaddam et al., 2020).

Every organization is an open and complex system that includes many variables and all of these factors are related to external environmental factors. Nowadays, the reduction of competitive advantage is seen more and more, while the business environment is constantly changing. Organizations are looking for more efficient and effective methods. We need to look for new solutions to increase work efficiency and focus on the goals of the organization, including goals related to continuous quality improvement. The methods of change in the last two decades according to quality goals, focus on increasing the effectiveness of organizations (Kull, Wacker, 2010). Service quality is defined as the 'global assessment or attitude of overall service excellence'; in other words, it is the difference between customer perception or expectation of service provided by service organizations using the theory of approval or disapproval (Afthanorhan et al., 2019). Pioneers of total quality management such as Deming, Jorn, Kozi, and Fingbaum see the importance of quality philosophy as an essential competitive weapon to become an outstanding organization (Jaafreh, Alabedallat, 2012). High-quality products and services help the organization retain its customers and increase their number, and lowquality leads to customer dissatisfaction and future loss of the organization (Striukova, Rayna, 2008).

On the other hand, organizational entrepreneurship in many countries, especially developing countries such as Iran, which has a traditional and resource-based economy, is in poor condition and lacks much development. According to the World Entrepreneurship Watch (2011), the level of organizational entrepreneurship in Iran is similar to that of the countries such as Bangladesh, Pakistan, and Jamaica less than $1 \%$, while for developed countries such as Sweden, Denmark, Belgium, Finland, and the United States varies between 6 and 14 percent (Kelley et al., 2012). Entrepreneurship is "a process that takes place over time and involves various stages from the intent to set up, launch, enhance, stabilize, and manage the business, exit, and re-entry". There are generally 2 approaches to define entrepreneurship in the psychological studies: 1: entrepreneurs as a job group that includes people who work and manage their businesses; 2: entrepreneurial processes and practices as those in Opportunities rely on, build and execute opportunities (Palazzeschi et al., 2018).

Numerous factors such as resource constraints, social problems, the downsizing of governments, inefficiency of traditional methods of public administration, rapid environmental changes, and the maintenance of efficient and skilled human resources have made entrepreneurship an alternative phenomenon in today's organizations. Organizational entrepreneurship is a subset of the overall concept of entrepreneurship and is meant to create and foster an entrepreneurial spirit in an organization. Designing organizational structures and systems that support organizational entrepreneurship, providing the resources needed to identify and exploit opportunities, such as human resources and technology, and developing an entrepreneurial culture within the organization are among the most important measures that must be taken to enable the organization to 
become an organizational entrepreneur (Morris et al., 2011). The present study aimed to present a framework for human resource productivity development and organizational excellence in executive organizations in Kerman by utilizing research and identifying barriers and bottlenecks, and emphasizing the two factors of quality and entrepreneurship.

Concerning this issue, the following research questions are:

1) Is there any relationship between quality and its dimensions with productivity management of the human resource in executive organizations in Kerman?

2) Is there a relationship between entrepreneurship and its dimensions with productivity management of the human resource in executive organizations in Kerman?

3) Is there a relationship between entrepreneurship and its quality dimensions in executive organizations in Kerman?

4) What are the characteristics of the designed model of human resource productivity management for organizational excellence with an emphasis on quality and entrepreneurship in executive organizations in Kerman?

5) Is the designed model of human resource productivity management optimal for organizational excellence with emphasis on quality and entrepreneurship in Kerman executive systems?

Given the importance of these factors and their relevance, previous studies and studies have examined the relationships and influences between these factors.

Purpose: This study aimed to identify and describe the human resource productivity management model.

Subject: The subject of research is to design a manpower productivity management model for organizational excellence with an emphasis on quality and entrepreneurship in Kerman executive agencies.
Çetin et al. (2012) examined how the EFQM model of excellence affects entrepreneurial behaviors within the organization and showed the positive impact of using the organizational excellence model on the emergence of entrepreneurial behaviors in the organization. In a study, Politis (2015) found that entrepreneurial orientation significantly influenced the dimensions of creativity and productivity. As a result, the findings clearly show that organizations need to retain employees who enhance creativity and productivity to promote positive and optimal behavior, such as setting goals, selfassessment, and so on. Nasution et al. (2016) found that leadership style variables, work ethics, and organizational atmosphere, affect employee productivity. Aspects of leadership style are more influenced by productivity than the other 3 elements, i.e., being on time, work quality, and workload. Chauhan and Nema (2017) found that TQM plays an important role in increasing productivity in the insurance sector. This indicates that post-quality assurance quality measures include: qualitative information, measurement criteria, statistical process control, and so on. Applying TQM concepts to the organization enhances employee productivity by reducing duplication of work, losses as well as minimizing mistakes. Given the explanations and research background of the study variables, the following are presented in the conceptual model:

The first variable to be considered in this study is human resource productivity management (as the criterion variable). The variable that is attempted by the variables of quality and organizational entrepreneurship and their components (as the predictor variable). Interpret, interpret, and explain. Moreover, the organizational entrepreneurship variable as a predictor variable can affect quality as the criterion variable.

Copyright (C 2021 Author(s), published by Vytautas Magnus University. This is an open access article distributed under the terms of the Creative Commons Attribution Non-Commercial 4.0 (CC BY-NC 4.0) license, which permits unrestricted use, distribution, and reproduction in any medium provided the original author and source are credited. The material cannot be used for commercial purposes. 


\section{Method}

This research is a developmental study purposefully, a mixture of quantity and qualityapproach, and a descriptive, correlational, case-study in terms of research methodology that has been conducted among the employees of the executive bodies of Kerman. The required data were collected through the field study. In the first step of collecting data and identifying indicators for the process of modeling the statistical population of the study, including experts in this field, experts in the field of management and administrative affairs were the most expert people in this field that 30 experts (Available, HR specialists and experts familiar with the productivity issue) were selected based on purposeful sampling Non-random and selective method. The final questionnaire was then developed after consensus on the indicators identified by the experts. The second step consisted of all employees of Kerman executive agencies that the size of the sample can be between 5 and 10 times the number of questionnaires using the structural equation approach and confirm at or factor analysis (Westland, 2010). The stratified sampling method was used among 57 government agencies in the form of 5 groups: (1) Services, (2) Cultural - Educational, (3) Headquarters - Ministerial, (4) State companies, and (5) Banks and Insurance. The sixth group, i.e., the classification of judiciallaw enforcement agencies, was not investigated due to information and security issues. Finally, 524 employees were selected by stratified random sampling in proportion to the community size.

\section{Method of Implementation and Data Analysis}

Descriptive and inferential statistics, structural equation approach, confirmatory and exploratory factor analysis, one-sample t-test, and Pearson correlation were utilized for data analysis. In this study, two questionnaires were used to collect the required data from the statistical population of experts, and three questionnaires were used for the statistical population of the staff. Content validity (expert opinion) and exploratory factor analysis were used to determine the validity.

The Kaiser-Meyer-Olkin criteria (KMO) is used to verify the validity of data and to evaluate the accuracy of sampling before factor analysis. According to the results of factor analysis, 42 sub-dimensions (indicators) related to human resource productivity management are summarized in 5 factors. According to the findings, the KMO value for sampling quality is 0.947 , which is an acceptable value. According to the results of factor analysis, 20 sub-dimensions (indicators) related to entrepreneurship are summarized in 4 factors. According to the findings, the KMO value for sampling quality is 0.921 , which is an acceptable value. Based on the results of factor analysis, 51 quality-related sub-indices are summarized in 9 factors. According to the results, the KMO value of the sampling quality is 0.977 , which is an acceptable value.

The average variance extracted was calculated according to the results of the confirmatory factor analysis of the reliability value of each of the research variables in the following table (Table 1).

\section{Table 1. Extracted variance of research variables}

\begin{tabular}{|l|l|l|}
\hline Variable & AVE & The number of variable components \\
\hline Entrepreneurship & 0.741 & 20 \\
\hline Quality & 0.845 & 51 \\
\hline Human Resource Productivity Management & 0.755 & 47 \\
\hline Acceptable value & $>0.5$ & \\
\hline
\end{tabular}

The composite reliability was calculated according to the results of the confirmatory factor analysis of the reliability value of each of the research variables in the following table (Table 2). 
Management Theory and Studies for Rural Business and Infrastructure Development eISSN 2345 - 0355. 2021. Vol. 43. No. 2: 249 - 258

Article DOI: https://doi.org/10.15544/mts.2021.21

Table 2. Composite reliability of research variables

\begin{tabular}{|l|l|l|}
\hline Variable & CR & The number of variable components \\
\hline Entrepreneurship & 0.912 & 20 \\
\hline Quality & 0.980 & 51 \\
\hline Human Resource Productivity Management & 0.938 & 47 \\
\hline Acceptable value & $>0.6$ & \\
\hline
\end{tabular}

Because $(\mathrm{CR})$ is $>0.7$ and greater than $\mathrm{AVE}$, and AVE is $>0.5$, therefore, convergent validity is also confirmed. The reliability of the questionnaire was estimated using Cronbach's alpha. Cronbach's alpha was 0.953 in the human resource productivity management questionnaire and 0.912 in entrepreneurship and 0.981in quality. For human resource productivity management questionnaire:

Predictive validity: In order to measure the predictive validity of the entrepreneurial variable as a dependent variable and using regression analysis, the regression show that the human resource productivity variable predicts 26 percent of the entrepreneurial variable. Common sample bias is (0.17) 2 $=0.0289$.

Discriminant Validity: MSV \& ASV less than AVE

$\mathrm{MSV}=.973 * .973=.947$

$\mathrm{ASV}=$

$(.869+.973+.959+.748+.772) / 5=.864$

$\mathrm{MSV}<\mathrm{AVE}$

ASV $<$ AVE

Convergent validity: AVE $<.5$

5 (Table 3).

Table 3. Discriminant Validity

\begin{tabular}{|l|l|l|l|l|l|}
\hline Variable & $\mathbf{1}$ & $\mathbf{2}$ & $\mathbf{3}$ & $\mathbf{4}$ & $\mathbf{5}$ \\
\hline 1.Individual factors & .755 & & & & \\
\hline 2.Organizational factors & .690 & .755 & & & \\
\hline 3.Complementary organizational factors & .659 & .612 & .755 & & \\
\hline 4.Occupational factors & .602 & .601 & .614 & .755 & \\
\hline 5.External organizational factors & .419 & .523 & .522 & .575 & .755 \\
\hline
\end{tabular}

AMOS and SPSS statistical methods and structural equation modeling approach based on path analysis, one-sample t-test, and Pearson correlation test were used for data analysis.

\section{Results}

Is there a relationship between quality and its dimensions with human resource productivity management in executive organizations of Kerman?
The results of structural equation modeling indicate that quality has a significant positive effect on human resource productivity management (0.438) in executive organizations of Kerman. In other words, by increasing the quality of Kerman's executive systems, human resource productivity management will be improved.

The relationship between variables (quantitative and normal data) was examined using Pearson correlation coefficient, and it was indicated that there is a significant

Copyright (C) 2021 Author(s), published by Vytautas Magnus University. This is an open access article distributed under the terms of the Creative Commons Attribution Non-Commercial 4.0 (CC BY-NC 4.0) license, which permits unrestricted use, distribution, and reproduction in any medium provided the original author and source are credited. The material cannot be used for commercial purposes. 
relationship between HRM, strategy, leadership, staff, processes-products-services, resources and partnership, employee and customer outcomes, community outcomes, and business results with HRM. (P-value $<0.05$ ) (Table 4).

Table 4. Surveying the relationship between quality components and human resource productivity management

\begin{tabular}{|l|l|l|l|l|l|l|l|l|l|l|}
\hline Variable & $\mathbf{1}$ & $\mathbf{2}$ & $\mathbf{3}$ & $\mathbf{4}$ & $\mathbf{5}$ & $\mathbf{6}$ & $\mathbf{7}$ & $\mathbf{8}$ & $\mathbf{9}$ & $\mathbf{1 0}$ \\
\hline $\begin{array}{l}\text { Human Resource Productivity } \\
\text { Management }\end{array}$ & 1 & & & & & & & & & \\
\hline Leadership & 0.742 & 1 & & & & & & & & \\
\hline Strategy & $0.722^{* *}$ & 0.833 & 1 & & & & & & & \\
\hline Employees & $0.717^{* * *}$ & 0.805 & 0.817 & 1 & & & & & & \\
\hline Resources and Partnerships & $0.723^{* *}$ & 0.775 & 0.815 & 1.866 & 1 & & & & & \\
\hline Processes-Products-Services & $0.742^{* *}$ & 0.757 & 0.804 & 0.813 & 0.844 & 1 & & & & \\
\hline Customers results & 0.651 & 0.616 & 0.667 & 0.682 & 0.671 & 0.764 & 1 & & & \\
\hline Employees results & $0.729^{* *}$ & 0.759 & 0.788 & 0.810 & 0.823 & 0.774 & 0.651 & 1 & & \\
\hline Community results & $0.692^{* *}$ & 0.696 & 0.725 & 0.741 & 0.757 & 0.754 & 0.701 & 0.774 & 1 & \\
\hline Business results & $0.722^{* *}$ & 0.740 & 0.781 & 0.803 & 0.808 & 0.758 & 0.663 & 0.825 & 0.792 & 1 \\
\hline
\end{tabular}

* Significant at the level of 0.05 , ** Significant at the level of 0.01

Given the positive calculated correlation coefficients, these relationships are direct (incremental). In other words, the HRM variable increases by increasing each quality component. According to the calculated correlation coefficients, it can be said that the relationship between leadership and processesproducts-services and HRM is more intense.

Is there a relationship between entrepreneurship and its dimensions with human resource productivity management in executive organizations in Kerman?

The results of the structural equation modeling indicated that entrepreneurship has a significant positive impact on productivity management $(0.451)$ in executive organizations in Kerman. In other words, human resource productivity management improves and increases with the increase of entrepreneurship in executive organizations in Kerman.

The relationship between variables (quantitative and normal data) was examined using the Pearson correlation coefficient and showed a significant relationship between individual characteristics, strategic variables, organizational characteristics, and external variables with HRM (p-value <0.05) (Table 5).

Table 5. Investigating the relationship between entrepreneurial components and human resource productivity management

\begin{tabular}{|l|l|l|l|l|l|}
\hline Variable & $\mathbf{1}$ & $\mathbf{2}$ & $\mathbf{3}$ & $\mathbf{4}$ & $\mathbf{5}$ \\
\hline Human Resource Productivity Management & 1 & & & & \\
\hline Individual features & $0.468^{* * *}$ & 1 & & & \\
\hline Strategic variables & $0.734^{* * *}$ & 0.395 & 1 & & \\
\hline Organizational features & $0.767^{* * *}$ & 0.378 & 0.821 & 1 & \\
\hline External variables & $0.655^{* *}$ & 0.385 & 0.732 & 0.777 & 1 \\
\hline
\end{tabular}

* Significant at the level of $0.05, * *$ Significant at the level of 0.01

Given the positive calculated correlation coefficients, these relationships are direct (incremental). In other words, HRM variable increases by increasing each entrepreneurship component. According to the calculated correlation coefficients, it can be said that the relationship between organizational characteristics and HRM is more intense. 
Is there a relationship between entrepreneurship and its dimensions with quality in executive organizations in Kerman?

The results of structural equation modeling indicated a significant positive effect of entrepreneurship on quality (0.930) in executive organizations in Kerman. In other words, quality improves and increases by increasing entrepreneurship in executive organizations in Kerman.
Pearson correlation coefficient was used to examine the relationship between variables (quantitative and normal data). The results of the correlation test indicate that there is a significant relationship between personal characteristics, strategic variables, organizational characteristics and external variables with quality in executive organizations in Kerman (p-value $<0.05)$ (Table 6).

Table 6. Surveying the relationship between entrepreneurship components and quality

\begin{tabular}{|l|l|l|l|l|l|}
\hline Variables & $\mathbf{1}$ & $\mathbf{2}$ & $\mathbf{3}$ & $\mathbf{4}$ & $\mathbf{5}$ \\
\hline Quality & 1 & & & & \\
\hline Individual features & $0.419^{* *}$ & 1 & & & \\
\hline Strategic variables & $0.806^{* *}$ & 0.395 & 2 & & \\
\hline Organizational features & $0.853^{* *}$ & 0.378 & 0.821 & 1 & \\
\hline External variables & $0.756^{* *}$ & 0.385 & 0.732 & 0.777 & 1 \\
\hline
\end{tabular}

** Significant at the level of $0.01, *$ Significant at the level of 0.05

Given the calculated positive correlation coefficients, these relationships are direct (incremental). In other words, the quality variable increases by increasing each entrepreneurial component. According to the calculated correlation coefficients, it can be said that the relationship between organizational characteristics and quality is more intense.

What are the characteristics of the designed model of human resource productivity management for organizational excellence with an emphasis on quality and entrepreneurship in executive organizations in Kerman?
The software output indicated the suitability of the research model so that the root mean square error of estimation (RMSEA) is $(0.064)$, the standardized chi-square value (CMIN/DF) is (3.116) and the goodness of fit index (GFI) is equal to (0.926) (Table 7).

Copyright (C 2021 Author(s), published by Vytautas Magnus University. This is an open access article distributed under the terms of the Creative Commons Attribution Non-Commercial 4.0 (CC BY-NC 4.0) license, which permits unrestricted use, distribution, and reproduction in any medium provided the original author and source are credited. The material cannot be used for commercial purposes. 
Management Theory and Studies for Rural Business and Infrastructure Development eISSN 2345 - 0355. 2021. Vol. 43. No. 2: 250 - 261

Article DOI: https://doi.org/10.15544/mts.2021.21

Table 7. Proposed research model fit indices

\begin{tabular}{|l|l|l|}
\hline Index & Acceptable limit & Reported value \\
\hline Root Mean Square Error of Estimation (RMSEA) & Equal to or less than 0.08 & 0.064 \\
\hline Normalized Chi-Square (CMIN / DF) & Equal to or less than 3 & 3.116 \\
\hline The goodness of fit index (GFI) & Equal to or more than 0.9 & 0.926 \\
\hline Modified goodness of fit index (AGFI) & Equal to or more than 0.9 & 0.897 \\
\hline Adaptive Fit Index (CFI) & Equal to or more than 0.9 & 0.973 \\
\hline Standardized Fit Index (NFI) & Equal to or more than 0.9 & 0.966 \\
\hline Tucker-Lewis Index (TLI) & Equal to or more than 0.9 & 0.961 \\
\hline Incremental Fit Index (IFI) & Equal to or more than 0.9 & 0.973 \\
\hline
\end{tabular}

The results indicated the significant positive effect of entrepreneurship on quality (0.930) and the significant positive effect of quality on HRM (0.438) as well as a positive and significant effect of entrepreneurship on HRM (0.451). In addition to direct impact, entrepreneurship affects human resource productivity management indirectly and through quality. The direct impact rate is (0.451) and the indirect impact through quality equals (0.407). Based on the calculations, a significant confidence interval was obtained from the Bootstrap method to examine the mediating role of the variable of equal quality $(0.374,0.155)$.

Is the designed human resource productivity model optimal for organizational excellence with emphasis on quality and entrepreneurship in Kerman executive systems?
The results indicate the significant positive effect of entrepreneurship on quality and the significant positive effect of quality on HRM and also the significant positive effect of entrepreneurship on HRM. In addition to direct impact, entrepreneurship affects human resource productivity management indirectly and through quality. The coefficients of the proposed path indicate that the relationship between entrepreneurship and manpower productivity management is more than the relationship between quality and manpower productivity management. Accordingly, the mediating effect of quality on the relationship between entrepreneurship and HRM is confirmed. In addition, based on R2, entrepreneurship explained $19 \%$ and quality $20 \%$ of changes in HRM management (Table $8)$.

\section{Table 8. Results of the research questions test}

\begin{tabular}{|l|l|l|l|l|}
\hline Uestion & Path coefficient & T statistics & $\begin{array}{l}\text { Type } \\
\text { relationship }\end{array}$ & $\begin{array}{l}\text { Type of } \\
\text { Fit }\end{array}$ \\
\hline Entrepreneurship $\rightarrow$ quality $\rightarrow$ Quality & 0.930 & ${ }^{* *} 22.47$ & Incremental & Optimal \\
\hline $\begin{array}{l}\text { Managing Productivity } \\
\text { Management }\end{array}$ & & $4.538^{* *}$ & Incremental & Optimal \\
\hline Managing Productivity $\rightarrow$ Entrepreneurship & 0.451 & $4.62^{* *}$ & Incremental & Optimal \\
\hline
\end{tabular}

Copyright (C) 2021 Author(s), published by Vytautas Magnus University. This is an open access article distributed under the terms of the Creative Commons Attribution Non-Commercial 4.0 (CC BY-NC 4.0) license, which permits unrestricted use, distribution, and reproduction in any medium provided the original author and source are credited. The material cannot be used for commercial purposes. 
Figure 1. Manpower productivity model (Mehtarizadeh et al., 2020

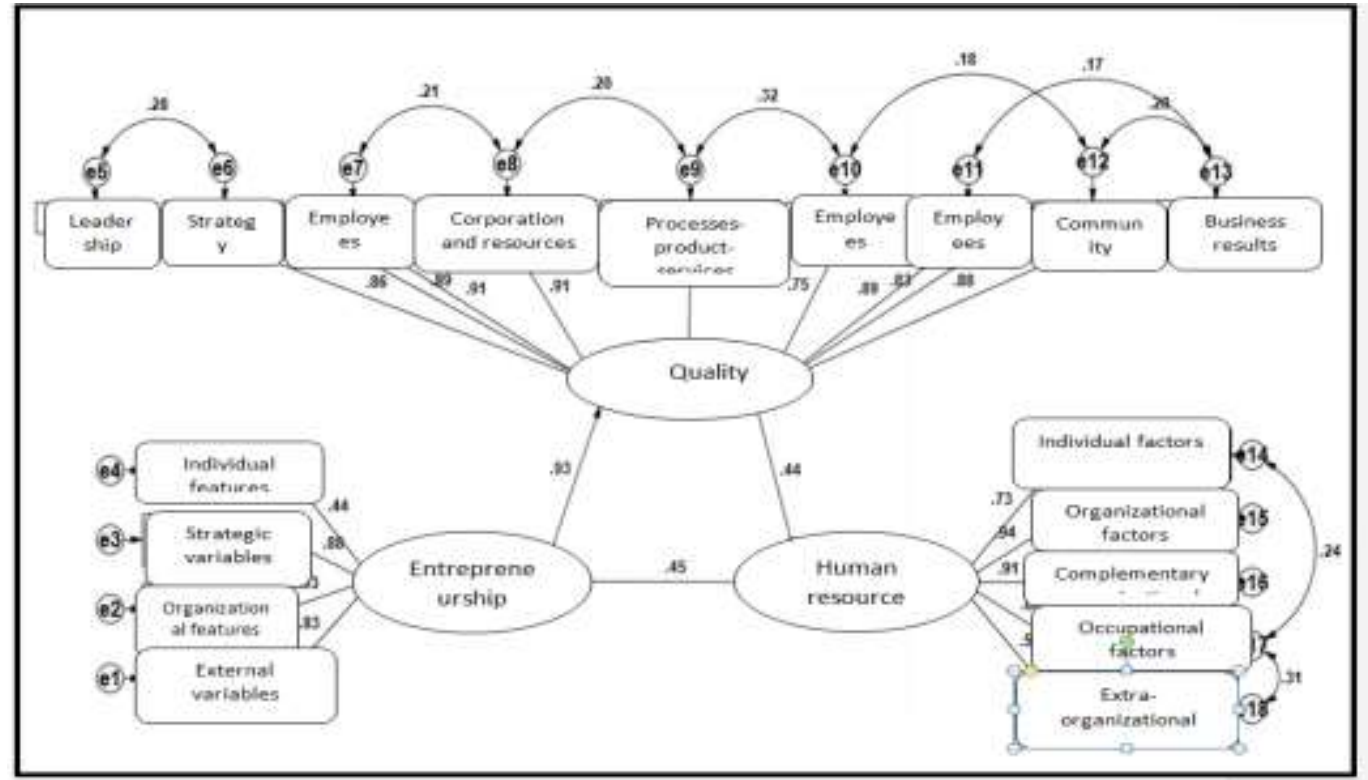

\section{Conclusion}

Paying attention to human resources is one of the most effective tools for achieving organizational excellence. Human resource productivity as a strategic tool for gaining competitive benefits is one of the majors' programs in organizations, so having qualified human resources with the characteristics, capabilities, and skills appropriate to the needs of today's organizations can form the competitive advantage of their organization.

From the results of this study, it can be concluded that quality has a significant positive effect on human resource productivity management in executive organizations of Kerman. Also, there was a significant relationship between HRM, strategy, leadership, staff, processes-products-services, resources and partnership, employee and customer outcomes, community outcomes, and business results with HRM.

Quality management and the application of organizational entrepreneurship in organizations lead to the development of human resource productivity. Therefore, the existence of quality and organizational entrepreneurship in organizations can lead to a valuable generation of productive employees.

Moreover, it was concluded that there is a significant relationship between personal characteristics, strategic variables, organizational characteristics, and external variables with quality in executive organizations in Kerman.

In addition, it was shown that there is a relationship between quality and productivity management in executive organizations in Kerman, so, it is suggested that managers should think about the necessity of conducting periodic evaluations to continuously improve the activities of organizations and ultimately improve the quality of services provided.

Given that there are potential entrepreneurs in the organization, they must provide the ground for their actual activities. Regarding the positive relationship between organizational entrepreneurship and quality in

Copyright (C) 2021 Author(s), published by Vytautas Magnus University. This is an open access article distributed under the terms of the Creative Commons Attribution Non-Commercial 4.0 (CC BY-NC 4.0) license, which permits unrestricted use, distribution, and reproduction in any medium provided the original author and source are credited. The material cannot be used for commercial purposes. 
executive organizations in Kerman, it is recommended that managers first address the expectations and needs of clients and create creative and innovative space to create entrepreneurial activities to provide quality services (speed, precision, cost, etc.)

\section{References}

Afthanorhan, A., Awang, Z., Rashid, N., Foziah, H., Ghazali, P. (2019). Assessing the effects of service quality on customer satisfaction // Management Science Letters. Vol. 9. No. 1: 13-24.

Alimohammadlou, M., Mohammadi, S. (2016). Evaluating the productivity using Malmquist index based on double frontiers data // Procedia-Social and Behavioral Sciences. Vol. 2. No. 3: 58-66.

Baboli M, Karimi H, Hayati Z, Hamedpour H, Joo A M, Binandeh M. (2020). //The Relationship between Cultural Intelligence and Organizational In-difference among Managers of Hospitals// Entomology and Applied Science Letters. Vol. 7. No. 4: 28-33.

Çetin, F., Şeşen, H., Basım, H. N. (2012). Exploring the Effects of EFQM Excellence Model on the Process of Intrapreneurship: A Research from Turkey // International Journal of Contemporary Economics and Administrative Sciences. Vol. 2. No. 4: 173-191.

Chauhan, G., Nema, G. (2017). Study of the Role of Total Quality Management in Productivity Enhancement in Indian Insurance Sector // Pacific Business Review International. Vol. 9. No. 11: 75-85.

Hashemy, S. H., Yousefi, M., Soodi, S., Omidi, B. (2016). Explaining human resource empowerment pattern and organizational excellence among employees of emergency of Guilan's University Hospitals // Procedia-Social and behavioral sciences. Vol. 23: 6-13.

Jaafreh, A. B., Al-abedallat, A. Z. (2013). The effect of quality management practices on organizational performance in Jordan: An empirical study // International Journal of Financial Research. Vol. 4. No. 1: 93-109.

Kelley, D. J., Singer, S., Herrington, M. (2012). Global entrepreneurship monitors 2011 global report. Global Entrepreneurship Research Association, London Business School.

Kull, T. J., Wacker, J. G. (2010). Quality management effectiveness in Asia: The influence of culture // Journal of Operations Management. Vol. 28. No. 3: 223-239.

Morgan, R. M., Hunt S. D. (2007). HRM: conceptualization and scale development // European Journal of Marketing. Vol. 39. No. 11: 1264-1290.

Morris, M. H., Kuratko, D. F., Covin, J. G. (2011). Corporate Entrepreneurship \& Innovation. - USA: SouthWestern College Pub.

Nasution, A. P., Mahargiono, P. B., Soesatyo, Y. (2016). Effect of leadership styles, organizational climate and ethos of work on employee productivity (PT. HP Metals Indonesia the Powder Coating) // Jurnal Dimensi. Vol. 5. No. 1: 262-273.

Palazzeschi, L., Bucci, O., Di Fabio, A. (2018). High Entrepreneurship, Leadership, and Professionalism (HELP): A New Resource for Workers in the 21st Century// Frontiers in Psychology. Vol. 9: 1480

Pokela, S. (2016). Strategic management of personnel productivity Case Study in Finnish healthcare organization. Master Thesis, Oulu Business School.

Politis, J. D. (2015). Entrepreneurial Orientation, Creativity, and Productivity: The influence of self-leadership strategies // Management. Vol. 3. No. 8: 203-213.

Prasad, K. D., Jha, S. K., Prakash, A. (2015). Quality, productivity and business performance in home-based brassware manufacturing units // International Journal of Productivity and Performance Management. Vol. 64. No. 2: 270-287.

Sergeevna, S. M., \& Efimovna, L. E. (2020). //Improving training of pharmaceutical specialists for consultation in pharmacy organizations using interactive forms of education// Pharmacophore, Vol. 11. No. 2: 7-14.

Striukova, L., Rayna, T. (2008). The role of social capital in virtual teams and organisations: corporate value creation. // International Journal of Networking and Virtual Organisations. Vol. 5. No. 1: 103-119.

Suwandej, N. (2015). Factors influencing total quality management // Procedia-Social and Behavioral Sciences. No. 197: 2215-2222.

Westland, J. C. (2010). Lower bounds on sample size in structural equation modeling// Electronic Commerce Research and Applications. Vol. 9. No. 6: 476-487.

Young Kim, D., Kumar, V., Murphy, S. A. (2010). European foundation for quality management business excellence model: an integrative review and research agenda // International Journal of Quality and Reliability Management. Vol. 27. No. 6: 684-701.

Zarei, Z., Afshari, P., Jahanbani, E., Haghighi, MH. (2020). //Evaluating the Effect of Leadership Style on Burnout among the Midwives Working at Maternity Hospitals of Khuzestan Province. // International Journal of Pharmaceutical and Phytopharmacological Research// Vol. 10. No. 1: 122-126. 